\title{
Numerical Modeling of Reinforced Concrete Beams Strengthened by NSM-CFRP Technique
}

\author{
Ahmed Khene ${ }^{1}$, Nasr-Eddine Chikh ${ }^{1}$ and Habib Abdelhak Mesbah ${ }^{2}$
}

\begin{abstract}
The NSM method has been used in recent years for the strengthening of RC beams with CFRP materials. A numerical study has been carried out on rectangular RC beams, strengthened with NSM-CFRP by using FE code ATENA. The numerical FE simulations were compared with experimental measurement tested by other investigators on specimen strengthened with NSM CFRP strips. On overall, the predicted FE peak loads and mid-span deflection responses agreed quite well with the corresponding measured experimental tested data at all stages of flexural loading. Therefore, the developed FE model is suitable as a practical and economical tool especially in parametric studies for accurate modeling and analysis of flexural strengthening of RC members with NSM-FRP reinforcement.
\end{abstract}

Keywords - RC Beam, NSM-CFRP, Strengthening, FE analysis.

\section{INTRODUCTION}

A civil engineering structure is designed for a lifetime of one hundred years on average. However, several types of disorders come forward to reduce this period of life, and now a building on three requires maintenance to ensure the safety of users. There are various methods of strengthening, but most of the old existing techniques have drawbacks such as the implementation of difficulty and low rates of input of resistance. However, reinforcement techniques using composite materials are more attractive because they offer many advantages with regard to mechanical properties and ease of execution. Among the strengthening methods available is the External Bonded Reinforcement (EBR) technique, which involves bonding of carbon fiber reinforcement polymers (CFRP) sheets or plates on the outer surface of the structural member with a suitable epoxy resin [1-3]. There is also the method Near Surface Mounted (NSM), which involves the insertion of CFRP strips or rods in notches carried out previously on the surface of the outstretched concrete and then filled with an epoxy resin for fixing. NSM method can be used for all building and all structural repairs of concrete, wood and especially in remote areas and on complex forms of work, it can be used in strengthening the flexure, the shear force, traction and containment [4-6]. Other work has been invested by the

\footnotetext{
${ }^{1}$ Civil Engineering Department (L.M.D.C), University of Mentouri Constantine, Constantine - 25000, Algeria

${ }^{2}$ Civil Engineering Department (L.G.C.G.M), University of Rennes 1, Rennes - Cedex 35043, France
}

authors to compare the EBR and NSM method [7-9] and has appeared with the NSM method the composite material is better optimized in terms of performance, because it slows premature detachment. Although NSM strengthening systems has been studied extensively [10-13], still further experimental, analytical, and numerical investigation is warranted to understand the effect of the several strengthening parameters on the flexural performance of $\mathrm{RC}$ members.

Experience has shown that exhaustive testing is a very expensive and time-consuming process and in recent years more emphasis has placed on numerical simulation complement testing. The development of high speed computers and more sophisticated non- linear constitutive material models capable of simulating exactly what happens experimentally has helped to make this transition. The objective of this paper is to numerically develop a $2 \mathrm{D}$ nonlinear finite element (FE) model that can accurately predicts the load-carrying capacity and response of reinforced concrete (RC) beams strengthened with NSM CFRP strips subjected to a 4 points flexural test using the FE code ATENA [14]. The developed FE models have been validated by comparing the predicted ultimate load and mid-span deflection with the measured experimental data obtained from previous research carried out by Hongseok et al. [15]. The parameters taken into account are the embedded length of CFRP plates and the strengthening ratio. The results of this study showed the practicality and validity of the FE method in modelling RC beams strengthened in flexure using NSM CFRP strip reinforcement.

\section{II.EXPERIMENTAL DETAILS}

The numerical analysis reported herein is based on the experimental results conducted by Hongseok et al. [15] that evaluated the response of $\mathrm{RC}$ members strengthened with NSM CFRP strips when subjected to a monotonically increasing four point bending up (two point loading) to failure of the specimen. The results indicated that the use of NSM reinforcement could significantly improve the flexural performance of the RC beams via increasing their ultimate moment capacities and limiting the beam's mid-span deflection at failure.

The experimental program consisted of ten strengthened $\mathrm{RC}$ beams in addition to an un-strengthened specimen to serve as a control beam. The beams had a total length of 3000 $\mathrm{mm}$ and of rectangular cross-section having a width and 
depth of $400 \mathrm{~mm}$ and $250 \mathrm{~mm}$, respectively. The longitudinal ribbed steel reinforcement consisted comprises two and three lower bars of $16 \mathrm{~mm}$ respectively for series 01 beams and series 2 beams as well as two $10 \mathrm{~mm}$ diameter bars in the compression zone (top reinforcement). In addition, $8 \mathrm{~mm}$ diameter steel stirrups were used as transverse reinforcement spaced $100 \mathrm{~mm}$ apart. The concrete cover is $40 \mathrm{~mm}$.

All beams of this study were made by using ready- mixed concrete with compressive strength of $30 \mathrm{MPa}$ at 28 days. The reinforcing steel bars have an elastic modulus of $200 \mathrm{GPa}$ and a yield strength of $350 \mathrm{MPa}$. The CFRP plates used present a cross section of $25 \times 1.2 \mathrm{~mm} 2$. Details of the positioning of reinforcements in the cross section are illustrated in Figure 1.

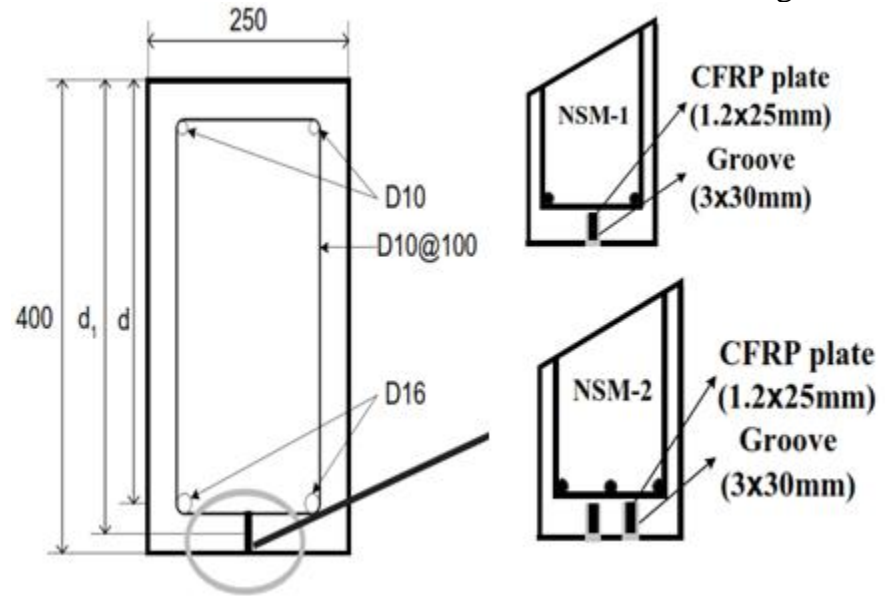

Fig. 1: Details of the strengthening cross-section

According to the manufacturer, the properties of the CFRP plates are as follows: $165 \mathrm{GPa}$ for the modulus of elasticity, $3160 \mathrm{MPa}$ for tensile strength and $2.0 \%$ for elongation at break. The main properties of the epoxy resin are given in Table I.
TABLE I

MECHANICAL PROPERTIES OF EPOXY RESIN

\begin{tabular}{lcc}
\hline \multicolumn{1}{c}{ Classification } & Results & Unit \\
\hline Tensile strength & 25.7 & $\mathrm{MPa}$ \\
Compressive strength & 85.6 & $\mathrm{MPa}$ \\
Modulus of elasticity & 2270 & $\mathrm{MPa}$ \\
\hline \hline
\end{tabular}

As shown in Figure 2, the pressing on a specimen was carried out in a 4-point loading method through a MTS company's hydraulic universal test machine with capacity of $250 \mathrm{kN}$ and its displacement control of $1 \mathrm{~mm} / \mathrm{min}$ was executed. The pressing point was positioned so that a/d become 3.7 in order to induce flexural failure.

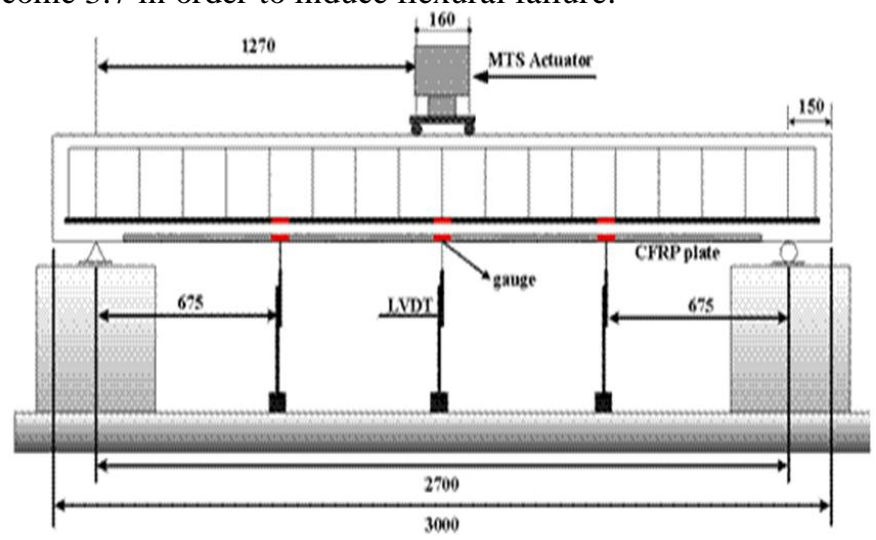

Fig. 2: Test Setup

The test parameters in this research are the CFRP reinforcement length $(32 \%, 48 \%, 70 \%, 80 \%$, and $96 \%$ of a span) and the number of stiffening members (one or two plates). The designation and the test parameters are shown in Table II.

TABLE II

DETAILS OF TEST SPECIMENS

\begin{tabular}{|c|c|c|c|c|c|c|c|c|}
\hline \multirow[t]{2}{*}{ Series } & \multirow[t]{2}{*}{ Designation } & \multirow{2}{*}{$\begin{array}{c}\text { Parameters of Concrete } \\
\text { Compressive Strength } \\
(\mathrm{MPa})\end{array}$} & \multicolumn{2}{|c|}{ Parameters of Steel } & \multicolumn{4}{|c|}{ Parameters of CFRP Plate } \\
\hline & & & $\begin{array}{l}\text { Diameter } \\
\text { (mm) }\end{array}$ & Number & $\begin{array}{l}\text { Thickness } \\
\text { (mm) }\end{array}$ & $\begin{array}{l}\text { Width } \\
\text { (mm) }\end{array}$ & Number & $\begin{array}{c}\text { Length } \\
\text { (mm) }\end{array}$ \\
\hline \multirow{4}{*}{ Series 01} & Ref-1 & 30 & 16 & 2 & - & - & - & - \\
\hline & NSM $1-48 \%$ & 30 & 16 & 2 & 1.2 & 25 & 1 & 1296 \\
\hline & NSM1-70\% & 30 & 16 & 2 & 1.2 & 25 & 1 & 1890 \\
\hline & NSM $1-80 \%$ & 30 & 16 & 2 & 1.2 & 25 & 1 & 2160 \\
\hline \multirow{5}{*}{ Series 02} & Ref-2 & 30 & 16 & 3 & - & - & - & - \\
\hline & NSM $2-32 \%$ & 30 & 16 & 3 & 1.2 & 25 & 2 & 864 \\
\hline & NSM2-48\% & 30 & 16 & 3 & 1.2 & 25 & 2 & 1296 \\
\hline & NSM2-70\% & 30 & 16 & 3 & 1.2 & 25 & 2 & 1890 \\
\hline & NSM2-80\% & 30 & 16 & 3 & 1.2 & 25 & 2 & 2160 \\
\hline
\end{tabular}

\section{III.. EXPERIMENTAL DETAILS}

In order to evaluate the performance of the NSM-CFRP strengthened RC beams, numerical FE analysis was performed using the software ATENA [14]. The fracture model was based on the classical orthotropic smeared crack formulation and crack band model. The concrete was modelled with Non Linear Cementitious 2D elements with a constituent plastic fracture model as shown in Figure 3. The steel reinforcement was modelled based on the bilinear law stress-strain as illustrated in Figure 4 and the CFRP strips supposed behave elastic up to failure. The measured material 
properties were used in the FE model, except for the CFRP strips which provider values were adopted. The steel reinforcement was supposed to have a perfect connection with the concrete.

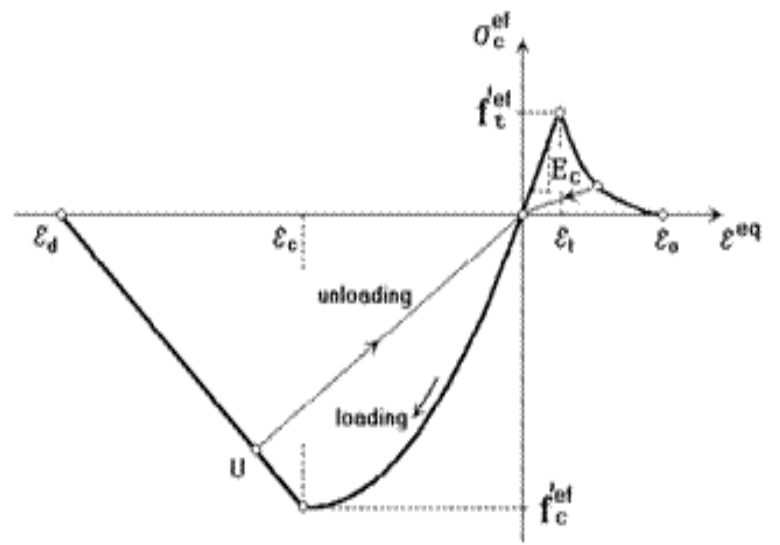

Fig. 3: Uniaxial stress-strain law for concrete

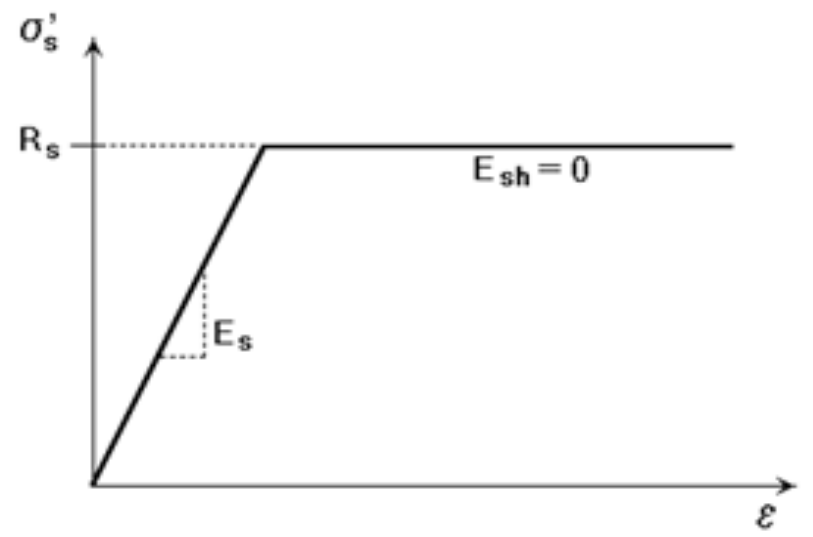

Fig. 4: Bilinear stress-strain law for reinforcement

The mid span model RC beam with the selected mesh is represented in Figure 5. The prescribed deformation was imposed for the model and the incrementing step by step has been adopted. Given that the beam is symmetrical, half the beam was modelled with suitable boundary conditions along the symmetry line. The developed FE model considers concrete material's nonlinearities in tension and compression, yielding of steel reinforcement, bond-slip action and concrete interfaces.

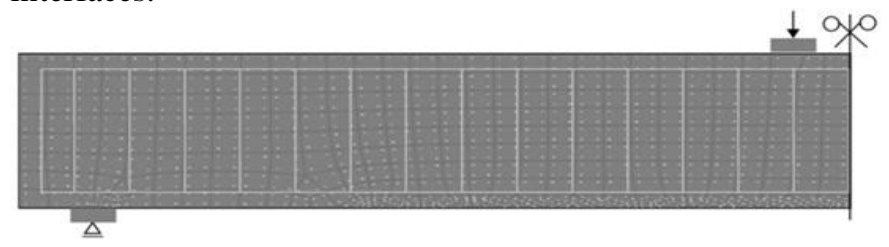

Fig. 5. RC beam model

\section{EXPERIMENTAL DETAILS}

In order to appraise the developed FE model and test its validity, a comparison between the FE numerical simulations and experimental results of Hongseok et al. [15] has been carried out. Figure 6 shows a comparison between the experimentally recorded and numerically simulated load midspan deflection of the control and the remaining strengthened RC beams. a) Ref-1

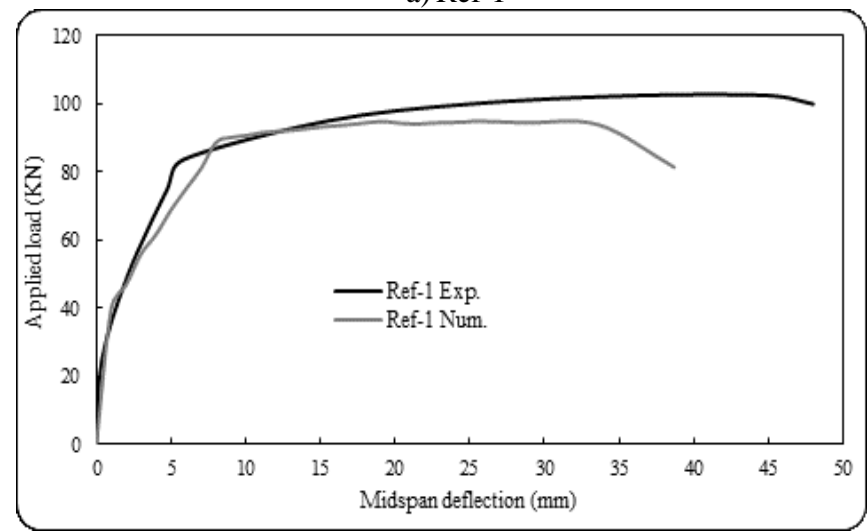

b) NSM1-32\%

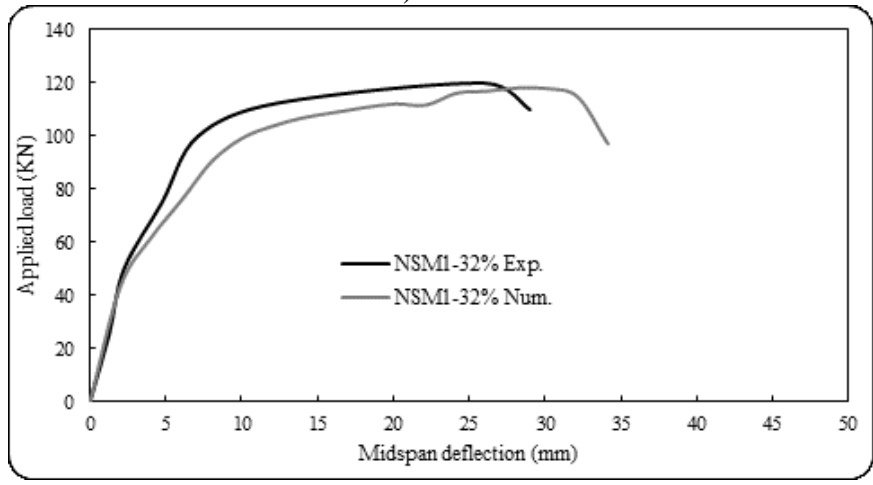

c) NSM1-70\%

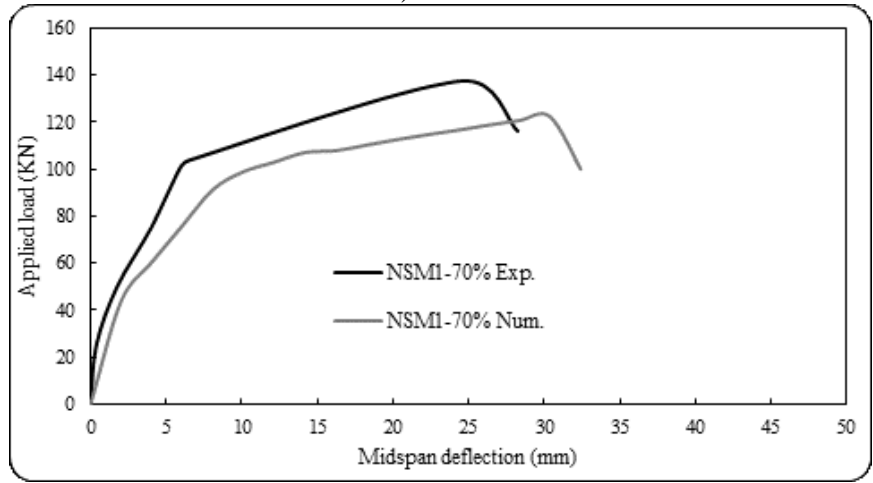

d) NSM1-96\%

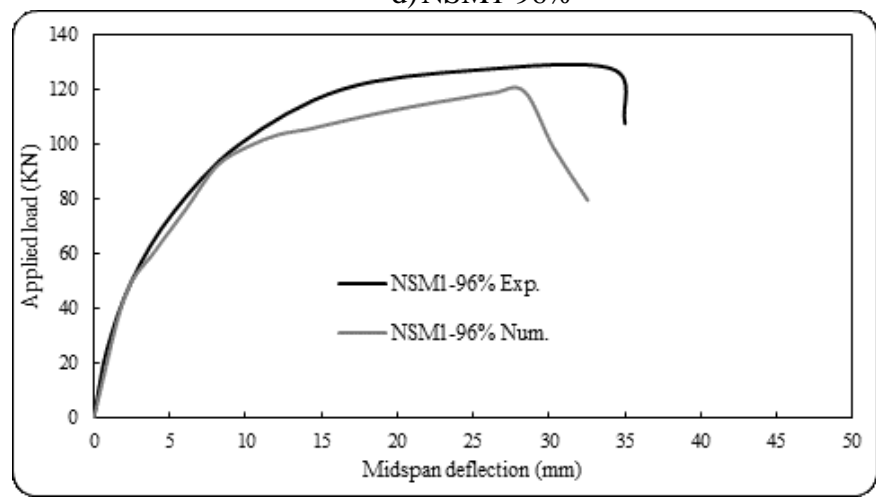

Fig. 6. Comparison between experimental measurements and FE simulation of the applied load-mid-span deflection response for the beam specimens presented in [15] 
e) Ref-2
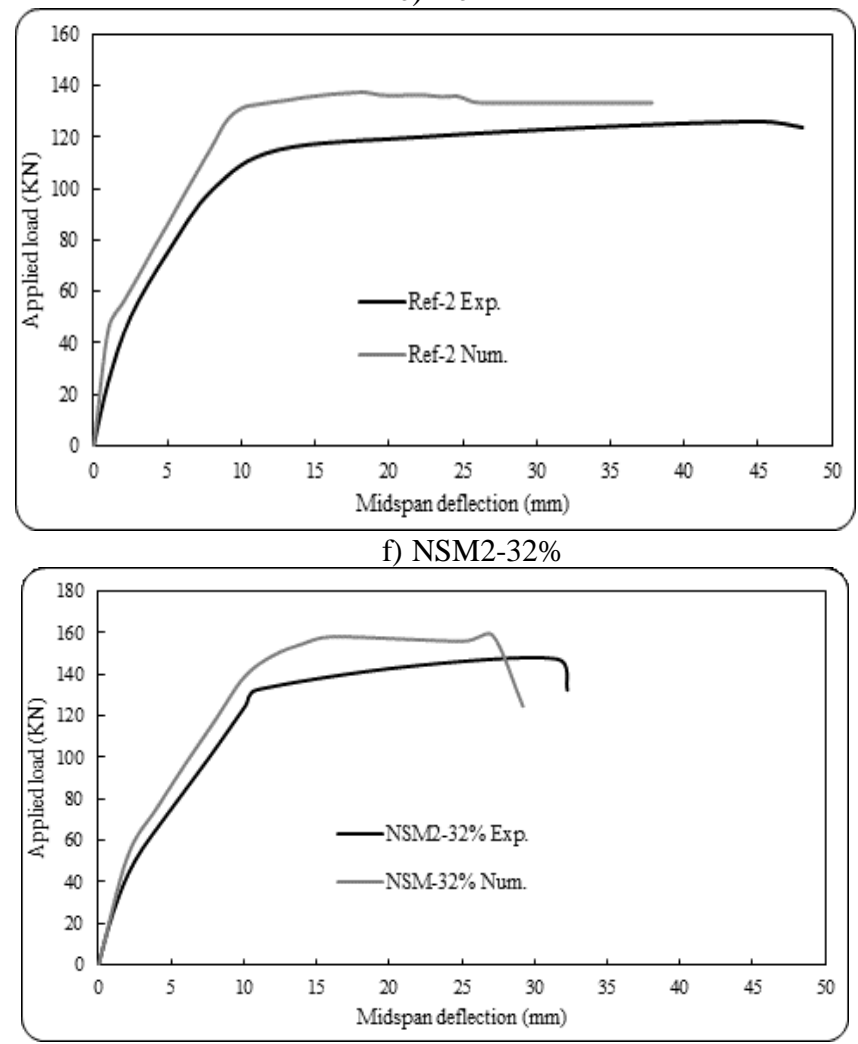

g) NSM2-70\%

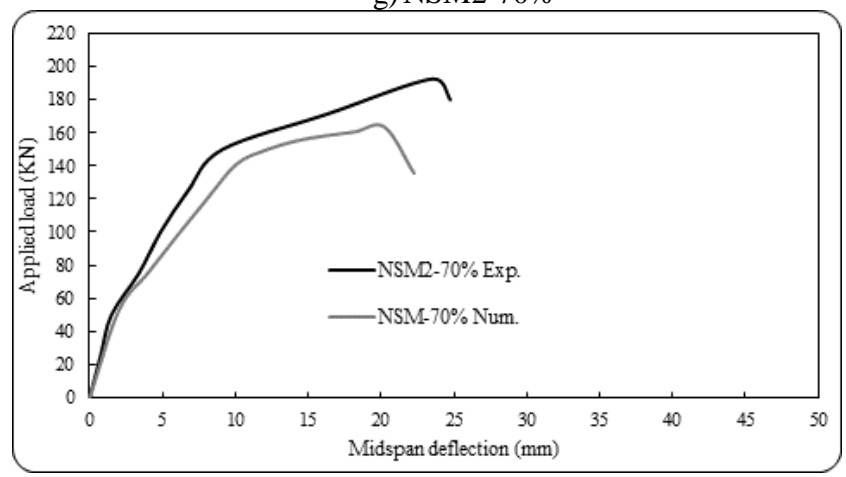

h) NSM2-96\%

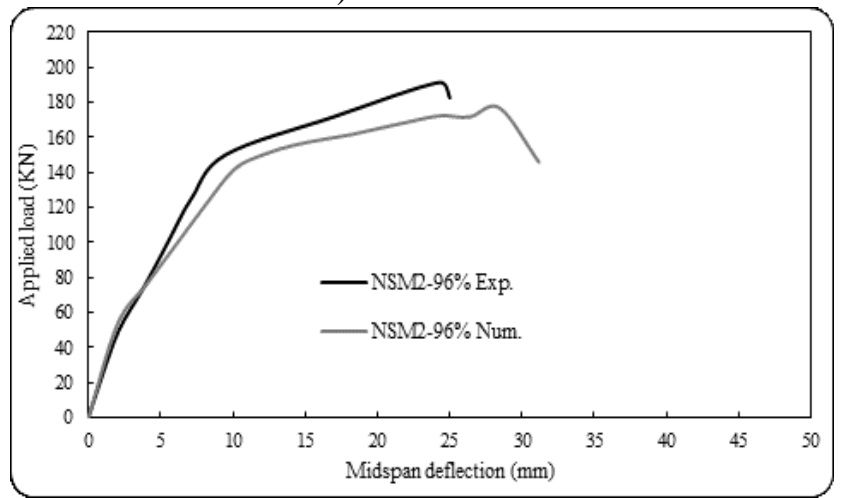

Fig. 6. Comparison between experimental measurements and FE simulation of the applied load-mid-span deflection response for the beam specimens presented in [15] (continued)

It is clear from Figure 6 that there is a quite good agreement between the predicted FE numerical simulations and experimental records at all stages of loading up to failure of the control and the NSM-CFRP retrofitted beams. As indicated in Table III, the maximum deviation between the experimental and predicted numerical results for the ultimate loading is less than $17 \%$ for the entire specimens whereas for the ultimate deflection it does not exceed $20 \%$. The developed model is capable of accurately performing parametric studies on different retrofitting configurations. Test results highlighted the high potential of the innovative composite systems for flexural strengthening applications. The reinforcement with NSM-CFRP strips has enhanced the beam performances beams in terms of both failure load and deflection.

TABLE III

COMPARISON OF EXPERIMENTAL AND NUMERICAL RESULTS

\begin{tabular}{|c|c|c|c|c|c|}
\hline \multirow[t]{2}{*}{ Series } & \multirow[t]{2}{*}{ Specimen } & \multicolumn{2}{|c|}{ Peak Loads } & \multicolumn{2}{|c|}{ Strengthening effect } \\
\hline & & $\begin{array}{c}\text { Experimental } \\
(\mathrm{KN}\end{array}$ & $\begin{array}{c}\text { Numerical } \\
(\mathrm{KN})\end{array}$ & $\begin{array}{c}\text { Experimental } \\
(\%)\end{array}$ & $\begin{array}{l}\text { Numerical } \\
(\%)\end{array}$ \\
\hline \multirow{6}{*}{ Series 1} & Ref-1 & 104.00 & 94.96 & - & - \\
\hline & NSM1-32 & 114.00 & 114.72 & 9.62 & 20.92 \\
\hline & NSM1-48 & 122.40 & 119.88 & 17.69 & 26.38 \\
\hline & NSM1-70 & 136.70 & 122.36 & 31.44 & 29.01 \\
\hline & NSM1-80 & 141.20 & 120.50 & 35.77 & 26.90 \\
\hline & NSM1-96 & 129.30 & 119.18 & 24.33 & 25.64 \\
\hline \multirow{6}{*}{ Series 2} & Ref-2 & 125.90 & 137.42 & - & - \\
\hline & NSM2-32 & 147.00 & 158.96 & 16.76 & 15.67 \\
\hline & NSM2-48 & 185.10 & 173.10 & 47.02 & 25.96 \\
\hline & NSM2-70 & 192.60 & 163.44 & 52.98 & 18.93 \\
\hline & NSM2-80 & 173.20 & 174.52 & 37.57 & 27.00 \\
\hline & NSM2-96 & 191.80 & 176.66 & 52.34 & 28.55 \\
\hline
\end{tabular}


As indicated in Table III, the maximum deviation between the experimental and predicted numerical results for the ultimate loading is less than $17 \%$ for the entire specimens whereas for the ultimate deflection it does not exceed $20 \%$. The developed model is capable of accurately performing parametric studies on different retrofitting configurations. Test results highlighted the high potential of the innovative composite systems for flexural strengthening applications. The reinforcement with NSM-CFRP strips has enhanced the beam performances beams in terms of both failure load and deflection

All the tested strengthened beams showed higher stiffness than their corresponding reference beams. As an analysis result of ultimate strength concerning reinforcement length, a trend of ultimate strength's increase appeared generally up to 0.70L of reinforcement length, but a lowering phenomenon of ultimate strength took place in case of $0.80 \mathrm{~L}$ and $0.96 \mathrm{~L}$. The bending capacity of the strengthened beams increases by up between $36 \%$ for one CFRP strip and up to $53 \%$ for two CFRP strips.

\section{V.CONCLUSION}

This numerical study was conducted to evaluate the performance of the reinforcement bending armed concrete beams with NSM-CFRP. Two parameters were considered. The developed model was validated by comparing $\mathrm{FE}$ numerical simulations with their corresponding experimental measurements available in the literature. According to the results, the following observations can be made:

- There is a quite good agreement between the experimental results and numerical simulations in terms of the load-deflection response at all stages of flexural loading up to failure of the specimen.

- Strengthening RC beams with NSM-CFRP strips increases their flexural strength. Their ultimate loadings increase with increasing the number of CFRP strips as well as with increasing the reinforcement length.

- The developed and validated finite element model presented in this study is suitable for modeling and analyzing RC beams strengthened in flexure using NSMCFRP strips. The developed model is capable of quite accurately and efficiently performing parametric studies on different retrofitting configurations using the NSM technique with FRP carbon plates.

\section{REFERENCES}

[1] A.L. Gamino, and T.N. Bittencourt, "Reinforced concrete beams strengthened with CFRP: experimental, analytical and numerical approaches," in Proc. FRPRCS-8 Symposium, Patras, 2007, pp. 1-10.

[2] A. Bilotta, C. Faella, E. Martinelli, and E. Nigro, "Design by testing procedure for intermediate debonding in EBR FRP strengthened RC beams," Engineering Structures, vol. 46, pp. 147-154, 2013.

[3] D. Mostofinejad, and A. T. Kashani, "Experimental study on effect of EBR and EBROG methods on debonding of FRP sheets used for shear strengthening of RC beams," Composites: Part B, vol. 45, pp. 1704-1713, 2013.

[4] L. De Lorenzis, "Anchorage length of near-surface mounted fiber reinforced polymer bars for concrete strengthening - analytical modeling," ACI Structural Journal, vol. 101, pp. 375-386, 2004.
[5] R. El-Hacha, and SH.Rizkalla, "Near-surface-mounted fiber-reinforced polymer reinforcements for flexural strengthening of concrete structures," ACI Structural Journal, vol. 101, pp. 717-726, 2004.

[6] J. Barros J, and AS Fortes, "Flexural strengthening of concrete beams with CFRP laminates bonded into slits," Cem Concr Compos, vol. 27, pp. 471480, 2005.

[7] O. Rosenboom, T. Hassan, and S. Rizkalla, "Flexural behavior of aged prestressed concrete girders strengthened with various FRP systems", Construction and Building Materials, vol. 21, pp. 764-776, 2007.

[8] H. A. Rasheed, R. R. Harrison, R. J. Peterman, and T. Alkhrdaji, "Ductile strengthening using externally bonded and near surface mounted composite systems," Composite Structures, vol. 92, pp. 2379-2390, 2010.

[9] A. Bilotta, F. Ceroni, E. Nigro, and M. Pecce, "Efficiency of CFRP NSM strips and EBR plates for flexural strengthening of RC beams and loading pattern influence," Composite Structures, vol. 124, pp. 163-175, 2015.

[10] D.J. Oehlers, R. Rashid, and R. Seracino, "IC debonding resistance of groups of FRP NSM strips in reinforced concrete beams," Construction and Building Materials, vol. 22, pp. 1574-1582, 2008.

[11] V. Bianco, J.A.O. Barros, and G. Monti, "Three dimensional mechanical model for simulating the NSM FRP strips shear strength contribution to RC beams," Engineering Structures, vol. 31, pp. 815-826, 2009.

[12] R.A. Hawileh, "Nonlinear finite element modeling of RC beams strengthened with NSM FRP rods," Construction and Building Materials, vol. 27, pp. 461-471, 2012.

[13] I.A. Sharaky, L. Torres, J. Comas, and C. Barris, "Flexural response of reinforced concrete (RC) beams strengthened with near surface mounted (NSM) fibre reinforced polymer (FRP) bars," Composite Structures, vol. 109, pp. 8-22, 2014.

[14] V. Cervenka, L. Jendele, and J. Cervenka, "Atena Program Documentation. Part. 1. Theory," Cervenka Consulting Ltd, Prague. 2010.

[15] O. Hongseob, S. Jongsung, J. Minkwan, and K. Hyunjoong, "The evaluation of structural performance for RC beams strengthened by NSM using CFRP plate," in Proc. Second Official International Conference of International Institute for FRP in Construction for Asia-Pacific Region, Seoul, 2009, pp. 525-532. 